\title{
Impact of employee age and work experience on safety culture at workplace
}

\author{
Abdul Aziz Mat Isa ${ }^{1 *}$, Warishah Abdul Wahab ${ }^{2}$, Rohayu Che Omar ${ }^{1 *}$, Mohd Zaid Mohd Nordin ${ }^{2}$, Hairin Taha ${ }^{1}$ and \\ Rasyikin Roslan ${ }^{1}$ \\ ${ }^{1}$ Institute of Energy Infrastructure, Universiti Tenaga Nasional,43000 Kajang, Malaysia EDP Sciences, Editorial Department, 91944 \\ Les Ulis Cedex A, France \\ ${ }^{2}$ College of Graduate Studies, Universiti Tenaga Nasional, Kajang, 43000, Malaysia
}

\begin{abstract}
Occupational accidents can be caused by different factors and can have many consequences, such as minor or fatal injury, equipment damage, permanent disability, or, in some cases, fatality. Therefore, it is essential to identify the causes of accidents to prevent them from recurring in the future and minimize injury, ill-health, and business costs. It is crucial, by determining the causes of the incident in the workplace, to analyse those that happened and take practical preventive steps to minimize the likelihood of them occurring again. A safe and accident-free working environment can allow the company to function efficiently and effectively. This study examined whether the age and experience of the employees, as determined by the demographics, have significant differences in the mean scores of the compliance towards safety culture within the company.
\end{abstract}

\section{Introduction}

\subsection{Age and work experience factor}

Safety practices in world industries are unique due to demographics, legislation, and stakeholder contractual agreements. Implementation of safety, health, and environmental management system is no widespread in developing countries [1], and Malaysia is not exceptional.

There are different generation cohorts in employment in a large organization, and each generation possesses different values, preferences concerning work motivation, and changes with their work environment. The individual in these generation cohorts is motivated by believing that they each share a different set of values and attitudes [2]. The main reason employees' age is considered an essential factor in this study is that technological and competency varies between age groups which affects their inclination on compliance of safety culture in the organization. Concerning generational differences, it is a significant area of concern and entails the management of an organization to analyse to leverage and better understand the behaviour of these generational groups [3].

In terms of age, multiple reasons may affect workers' productivity base on the years of work experience, physical abilities, work demands, academic background, family and care commitments, motivation and energy, loyalty, and personality factors. It has been reported that the declination of job performance is directly correlated to workers' age. However, it is less impactful on professions that do not require abilities by age, such as physical demand jobs [4].

According to [5], safety culture perceptions are influenced by demographic factors such as age, education, and experience. Workers who had been working for almost two decades are better informed and had better views about the importance of safety. On the other hand, employees at an early stage of their career would be interested in safety but gradually decrease due to company policies. They would prioritize safety at the peak of their career. Maturity may play roles later in their service life, equipped with experience that helps them address safety aspects and identify hazardous situations. A study indicated a positive relationship between age and safety perception. The study found that those older workers had the best perceptions on safety, indicated the highest level of job satisfaction, were the most compliant with safety procedures, and recorded the lowest accident involvement rate [6].

Some may be used to routine jobs described in their job scope, deterring empowerment from participating in a safety knowledge-sharing environment. May it be a different age group or work experience; every employee belongs to diverse generational cohorts. It is found that generational diversity existed in the workplace since different employees have clear expectations for their careers, work habits, life goals, and attitudes [7]. This research also emphasized that younger generations are less committed to organizations and more committed to their profession. Consequently, job commitment is one of the human aspects of employees' satisfaction and

\footnotetext{
*Corresponding author: azan@uniten.edu.my, rohayu@uniten.edu.my
} 
morale, which inevitably affects their safety compliance and safety performance.

From a practical perspective, understanding agerelated perceptions of workplace safety would influence management's decisions regarding workers' adaptability, work effectiveness, accident frequency, and implementation of safety management policies. Job position at different levels within an organizational structure is another important consideration of safety practice and performance evaluation. Job position abided by specific job titles and job descriptions enfold employees with a particular set of roles, expectations, duties, and responsibilities, to the extent that it may limit workers to unleash their full potentials.

\subsection{Compliance with safety culture}

Safety compliance is defined as adhering to safety policies and procedures and engaging in the required safety behaviour [8]. Safety compliance sets out clear guidelines that employees should follow to create a safe working environment. Safety compliance consists of required or expected behaviours to be part of the obligations and responsibilities of the assigned role, i.e. intra-role behaviours related to safety. These behaviours range from complying with standard work procedures, wearing personal protective equipment, and reporting incidents [9]. Compliance with safety and commitment have had a significant impact on work-related injuries [10]. Besides, people, the environment, and the economy may have to face the consequences of industrial or occupational accidents. Therefore, it is essential to solving the safety problems at the managerial level to prevent accidents and reduce economic losses [11].

Management should implement compliance programs consisting of periodic monitoring and auditing, particularly the high-risk areas identified by the risk assessment. These compliance programs focus on risk control measures and means of controlling workers' behaviour to comply with prescribed safe practices. The roles of program managers are to monitor their operations, keep up to date with current legal and regulatory requirements, translate this information into written guidance for their staff, train their staff on how to follow them, and keep in mind that they do so accordingly [12]. In short, there should be frequent external auditor audits to verify any inadequacy in meeting the safety guidelines [13]. The involvement of management and employees' compliance with safety procedures is essential for creating a safer environment in the workplace.

On the contrary, safety literature also suggested that a safe environment does not necessarily depend on compliance on its own. Compliance is complex and dynamic environments may, in certain circumstances, include rules and procedures that appear to be ambiguous, contradictory, complicated, confusing, or inadequate (non-applicable) to existing situational constraints. It has also been reported that certain factors that may cause severe or loss of time injuries are uncontrollable to employees (e.g., the environment or machinery). However, employees have the power to display safety behaviours at work, and these behaviours are critical indicators of accidents and injuries at work [14].

Safety culture is a subset of corporate culture within the organization. It has characteristics that can support safety, quality, productivity and directly affect safety performance. Safety culture is the attitude, beliefs, perceptions, and values of workers on safety issues when carrying out their day-to-day operations to achieve an interdependent safety culture. An example of a safety culture is the "first safety" practice, reflecting the importance of safety in the way people believe, think and act in creating a safe working environment. Safety culture needs to be part of the organizational culture that underpins management and affects workers' attitudes and behaviour to the organization's ongoing safety performance.

The study filled the gaps in the literature by testing the following two (2) hypotheses; (H1) There is a significant difference between the age of employees and the compliance of the safety culture within the organization under study; (H2) There is a substantial difference between the work experience of employees and the compliance of the safety culture within the organization under investigation.

\section{Materials and methods}

The research methodology of this study is divided into three phases, including the Survey Questionnaire Design, Survey Questionnaire Distribution, and Inferential Statistics, as shown in Figure 1.

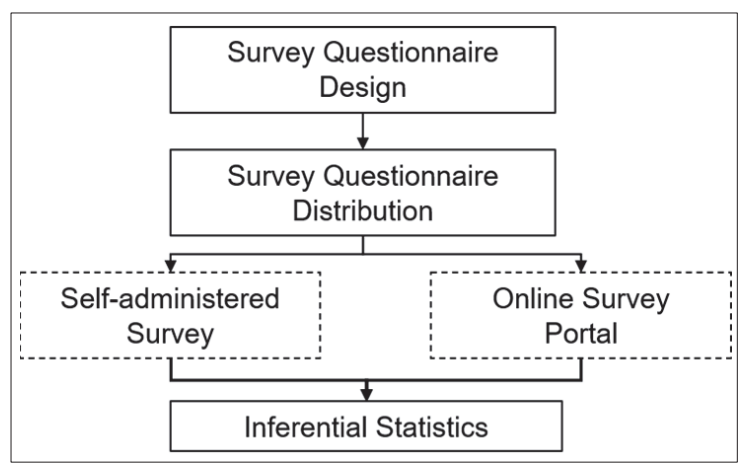

Fig. 1. Research methodology.

\subsection{Survey questionnaire design}

The questionnaire design process follows various steps, such as developing the conceptual framework, the construction of questionnaire questions, the selection of the proper questionnaire design, and the technical implementation of the softcopy questionnaires.

\subsection{Survey questionnaire distribution}

Data collection for this study is done using a selfgoverning survey method and the https:/docs.google.com ('Google Docs') online survey portal. Questionnaire surveys were distributed to the 200 executives and 200 non-executives from one 
Government Link Company (GLC) in order to explore the relationship between variables and help to confirm or reject the assumptions derived for this study. However, by the end of the survey period, only 257 responses were collected, which equals $64.3 \%$ out of the total employees who participated. The survey period was approximately one month in April 2019.

There are a few advantages to using an online survey. Less time is needed to conduct an online survey compared to traditional manual research methods. It is also not expensive, as it was unnecessary to spend on postage. Besides, online surveys take less time to enter the information in the database as the responses are transferred automatically, and the results are available at any time. The margin of error is significantly reduced with online surveys.

Currently, most people prefer to respond to online surveys using smartphones to complete the survey anytime and anywhere. It also provides convenience to respondents as it is mobile and adopts a green approach with less or no use of papers. The questionnaire in this study was designed to be concise and straightforward, in the format of pre-coded closed-ended questions. The questionnaire was also prepared in bilingual form (English and Malay). A great deal of attention focuses on the wording, structure, and layout of the questionnaire to avoid any misunderstanding among the respondents in answering all the questions.

\subsection{Inferential statistics}

Inferential statistics help to make judgments and to observe the difference between the mean groups in this study. Most of the significant inferential statistics come from the General Linear Model, which includes the TTest, Variance Analysis (ANOVA), Covariance Analysis (ANCOVA), and Regression Analysis. In this study, ANOVA was used to provide information on mean group variability levels and to compare mean group variability. The primary purpose of ANOVA is to determine whether there is an interaction between the mean groups, such as independent variables, and demographic information on the dependent variable.

The factors that influence the dependent variable that is hypothesized earlier can be investigated. The FTest One Way ANOVA test is performed to compare the variability of scores between different groups. For this study, the test will determine whether the age and years of experience of employees have significant differences in the mean safety compliance scores for Government Link Company (GLC) safety culture.

According to Rumsey (2016), in the end, all hypothesis tests use a p-value to weigh the strength of the evidence. The p-value of less than 0.05 indicates strong evidence against the null hypothesis that the null hypothesis must be rejected. A significant p-value higher than 0.05 shows weak evidence against the null hypothesis.

\section{Results}

This section may be divided into subheadings. It should provide a concise and precise description of the experimental results, their interpretation, and the experimental conclusions that can be drawn.

Survey questionnaires were distributed to 200 executives and 200 non-executives of the Government Link Company (GLC) networks. However, by the end of the survey period, 257 responses were collected, equivalent to 64.3 percent of the total staff involved. Compared to the total population of 10,431 in this Government Link Company (GLC) network, the respondents represent $2,5 \%$ of the total population with an error margin of $5 \%$ and a confidence level of $95 \%$. In the study, two research questions need to be answered. Research Question 1 questioned whether there is a significant difference between the age of employees and the safety culture of the organization understudy? Whereas the second research question asked whether there was a significant difference between the work experience of employees and the compliance of the safety culture within the organization understudy?

An inferential test is being conducted to determine whether the age and years of experience of employees based on demographics have significant differences in the mean scores of safety culture compliance within the Government Link Company (GLC) network.

Table 1 shows the One-Way ANOVA as a result of compliance of safety compliance within the organization based on the age group of employees. The ANOVA One-Way study was conducted to determine whether population demography has significant differences in mean scores on Government Link Company (GLC) network safety culture compliance.

Table 1. One-way ANOVA result of safety compliance based on the age group of the employees.

\begin{tabular}{|c|c|c|c|c|c|c|c|c|}
\hline \multirow{2}{*}{ Age group } & \multirow{2}{*}{$\mathbf{N}$} & \multirow{2}{*}{ Mean } & \multirow{2}{*}{ Std. deviation } & \multirow{2}{*}{ Std. error } & \multicolumn{2}{|c|}{$95 \%$ confidence interval for mean } & \multirow[b]{2}{*}{ Min. } & \multirow{2}{*}{ Max. } \\
\hline & & & & & Lower bound & Upper bound & & \\
\hline 22 years and below & 2 & 5.4444 & 0.78567 & 0.55556 & -1.6146 & 12.5034 & 4.89 & 6.00 \\
\hline $23-28$ years & 13 & 5.3248 & 0.44781 & 0.12420 & 5.0542 & 5.5954 & 4.22 & 5.78 \\
\hline $29-34$ years & 85 & 5.0719 & 0.59061 & 0.06406 & 4.9445 & 5.1993 & 3.67 & 6.00 \\
\hline $35-40$ years & 77 & 4.9957 & 0.57832 & 0.06591 & 4.8644 & 5.1269 & 3.89 & 6.00 \\
\hline 41 years and more & 80 & 5.0194 & 0.63688 & 0.07121 & 4.8777 & 5.1612 & 3.33 & 6.00 \\
\hline Total & 257 & 5.0484 & 0.59759 & 0.03728 & 4.9750 & 5.1218 & 3.33 & 6.00 \\
\hline \multicolumn{9}{|c|}{ ANOVA } \\
\hline & \multirow{2}{*}{\multicolumn{2}{|c|}{ Sum of Squares }} & df & Mean Square & \multicolumn{2}{|l|}{$\mathbf{F}$} & \multicolumn{2}{|c|}{ Sig. } \\
\hline Between Groups & & & 4 & \multirow{2}{*}{$\begin{array}{l}0.409 \\
0.356\end{array}$} & 1.147 & \multicolumn{3}{|c|}{.335} \\
\hline Within Groups & \multicolumn{2}{|c|}{$\frac{1.635}{89.787}$} & 252 & & & & & \\
\hline Total & \multicolumn{2}{|c|}{91.422} & 256 & & & & & \\
\hline
\end{tabular}


The interpretation of the ANOVA test is that the significant value ( $p$-value) of less than the 5-007 value of 0.05 indicates strong evidence against the null hypothesis that there is a significant difference. A sizeable significant value ( $\mathrm{p}$-value) greater than the 5007 value of 0.05 indicates weak evidence against the null hypothesis that there is no significant difference.

From Table 1, one-way ANOVA shows that there is no statistical difference between the average age group of employees. The result shows that the significant value (p-value) is 0.335 , which is greater than 0.05 (pvalue $>0.05)$ for the employee age group $[F(4,252)=$ $1.147, \mathrm{p}=0.335]$. The above analysis indicates no significant difference between the age group of employees and safety compliance with the organization's safety culture.

Post-hoc comparisons using Tukey HSD in the ANOVA test indicated that the maximum mean score for the employee age group within 22 years and below $(\mathrm{M}=5.44, \mathrm{SD}=0.79)$ was not significantly different from the lowest mean score for the employee age group between 35 and 40 years $(\mathrm{M}=5.00, \mathrm{SD}=0.58)$. The small difference in the mean value of the score between

Table 2. One-way ANOVA Result of Safety Compliance based on the employees' work experience.

\begin{tabular}{|c|c|c|c|c|c|c|c|c|c|}
\hline \multirow{2}{*}{\multicolumn{2}{|c|}{ Work experience group }} & \multirow{2}{*}{$\mathbf{N}$} & \multirow{2}{*}{ Mean } & \multirow{2}{*}{ Std. Deviation } & \multirow{2}{*}{$\begin{array}{c}\text { Std. } \\
\text { Error }\end{array}$} & \multicolumn{2}{|c|}{$95 \%$ confidence interval for mean } & \multirow{2}{*}{ Min. } & \multirow{2}{*}{ Max. } \\
\hline & & & & & & Lower Bound & Upper Bound & & \\
\hline 5 years and less & & 14 & 5.0952 & 0.71327 & 0.19063 & 4.6834 & 5.5071 & 3.89 & 6.00 \\
\hline $6-10$ years & & 80 & 5.0417 & 0.54559 & 0.06100 & 4.9203 & 5.1631 & 3.67 & 6.00 \\
\hline $11-15$ years & & 59 & 5.1299 & 0.55177 & 0.07183 & 4.9862 & 5.2737 & 4.00 & 6.00 \\
\hline $16-20$ years & & 36 & 4.8981 & 0.67944 & 0.11324 & 4.6683 & 5.1280 & 3.89 & 6.00 \\
\hline $21-25$ years & & 49 & 5.0884 & 0.64867 & 0.09267 & 4.9021 & 5.2748 & 3.44 & 6.00 \\
\hline $26-30$ years & & 5 & 5.1556 & 0.50062 & 0.22388 & 4.5340 & 5.7772 & 4.67 & 6.00 \\
\hline 31 years above & & 14 & 4.9048 & 0.59574 & 0.15922 & 4.5608 & 5.2487 & 3.33 & 6.00 \\
\hline Total & & 257 & 5.0484 & 0.59759 & 0.03728 & 4.9750 & 5.1218 & 3.33 & 6.00 \\
\hline \multicolumn{10}{|c|}{ ANOVA } \\
\hline & \multicolumn{3}{|c|}{ Sum of Squares } & df & \multicolumn{2}{|c|}{ Mean Square } & $\mathbf{F}$ & \multicolumn{2}{|c|}{ Sig. } \\
\hline Between Groups & \multicolumn{3}{|c|}{1.664} & 6 & \multicolumn{2}{|c|}{0.277} & 773 & \multicolumn{2}{|c|}{.592} \\
\hline Within Groups & \multicolumn{3}{|c|}{89.758} & 250 & \multicolumn{2}{|c|}{0.359} & & & \\
\hline Total & \multicolumn{3}{|c|}{91.422} & 256 & & & & & \\
\hline
\end{tabular}

Post-hoc comparisons using Tukey HSD in the ANOVA test indicated that the highest mean score was recorded for employees with work experience between 26 years and 30 years of age $(\mathrm{M}=5.16, \mathrm{SD}=0.50)$, which was not significantly different from the lowest mean score for employees with work experience between 16 and 20 years of age $(\mathrm{M}=4.90, \mathrm{SD}=0.68)$. The small difference in the mean value of the score between the employees ' work experience group supports the $p$-value $>0.05$. It shows that there is no significant difference between employees ' work experience and safety compliance with the organization's safety culture. H2 hypothesis rejected: there is a significant difference between the work experience of employees and the compliance of the safety culture within the organization under the study.

\section{Discussion}

the age group of employees supports the result of pvalue $>0.05$. It shows that there is no significant difference between the age group of employees and safety compliance with the organization's safety culture. Therefore, the $\mathrm{H} 1$ hypothesis: State significant difference comparing the age of the employees and the compliance of safety culture within the organization under study is being rejected.

Table 2 below shows the One-Way ANOVA result of the compliance of safety compliance within the organization based on the employees' work experience. One-way ANOVA analysis of variance showed no statistical difference between the mean numbers of the employees' work experience. The result shows that significant value ( $\mathrm{p}$-value) is 0.592 which is greater than $\alpha$ value of 0.05 ( $p$-value $>0.05$ ) for the work experience group of employees $[\mathrm{F}(6,250)=0.773, \mathrm{p}=0.592]$. The analysis indicates that there is no significant difference between the work experience of employees and the safety compliance towards the safety culture in the organization. 
knowledge, work experience skills, and high selfmotivation to learn. In the case of Government Link Company (GLC), workers over 55 years of age have the option of continuing to work until 60 years due to increases in the official retirement age. It will be difficult to predict the effects that changes in age and work experience may have on the performance of safety at work; those workers who continue to work longer may be exposed to occupational hazards.

\section{Conclusion}

Age and work experience are not the only factors that affect safety performance at work, although health and physical ability may change with age. In certain circumstances, employees with a health problem can adjust their daily work and activities to continue to work. The attitude of employees is the most significant barrier to working with a health problem rather than the health condition itself. Health is influenced by several other external factors, including lifestyle, exercise, and nutrition, in which age is not the only factor determining the level of health. Consideration of the workability of the immediate manager and supervisor is the most appropriate way to determine whether or not any change in the health or capacity of the worker puts them at an increased risk and risk from their work. Each individual's resources shall be considered in deciding the requirements of the employer's job. Older and experienced workers need to be identified as valuable assets to the company. Generally, this organizational group tends to be more resourceful in completing their work and with a high degree of determination to ensure that their tasks are well managed, regardless of age or work experience.

The research presented in this paper was funded by Tenaga Nasional Berhad (TNB) through a post-graduate university scholarship (UNITEN) and UNITEN R \& D Sdn. Bhd. under URND Seeding Fund (U-TE-RD-19-19). The authors would like to thanks Universiti Tenaga Nasional (UNITEN) and UNITEN R \& D Sdn. Bhd. for the opportunity and sponsorship in completing this study.

\section{References}

1. E. Koehn, R. Kothari, C. Pan, J. of Construction Engineering \& Management 121, 3:261-265 (1995)

2. E. Parry, P. Urwin, IJMR 13, 1:79-96 (2011)

3. M.S. White, C. Burns, and H. A. Conlon Workplace Health \& Safety, SAGE Journal 66, 10: 493-498 (2018)

4. V. Skirbekk, Ageing Horizons 8, 4-8 (2008)

5. R. Masood, R. Choudry (2012). Investigation of demographic factors relationship with safety climate, in 48th ASC Annual International Conference Proceedings (2012)

6. C. Pfeifer, J. Wagner, Contemporary Economics 8, $1: 25-46(2014)$
7. A. Singh, B. Gupta, Benchmarking: An International Journal, 2015 22, 6:1192-1211 (2015)

8. Y. Feng, E. A. L. Teo, F. Y. Y. Ling, S. P. Low, International Journal of Project Management 32, 6:932-943 (2014)

9. M. Martinez, F. Gracia, I. Tomas, J. Peiro, Risk Analysis 34, 7 (2014)

10. J. Nahrang, F. Morgeson, D. Hofmann, A metaanalytic investigation of individual and contextual influences on workplace safety, satisfaction, and well-being (The Society for Industrial and Organizational Psychology, San Francisco, 2008)

11. Z. Lin, Using TOC thinking process tools to improve safety performance (Department of Computer Science, Shangluo University, Shaanxi, China, 2009)

12. R. Kusserow, J. of Health Care (2017)

13. P. Mitropoulos, G. Cupido, M. Namboodiri, J. Constr. Eng. Manage. 135, 9:881-889 (2009)

14. A. Ghahramani, H. R. Khalkhali, Safety \& Health at Work 6, 2:97-103 (2015)

15. D. Rumsey, Statistics for dummies 2nd edition. (John Wiley \& Sons. Inc, United States, 2006)

16. J. O. Crawford, A. Davis, H. Cowie, K. \& Dixon, $\mathrm{K}$. The ageing workforce: implications for occupational safety and health (European Agency for Safety and Health at Work, 2016) 